\title{
Dynamic Amide Formation by Reversible Nitrone Exchange of Potassium Acyltrifluoroborates (KATs) and Hydroxylamines in Aqueous Conditions
}

\author{
Yi-Chung Dzeng and Jeffrey W. Bode * \\ Department of Chemistry and Applied Biosciences \\ ETH Zürich \\ Zürich, Switzerland \\ bode@org.chem.ethz.ch
}

\begin{abstract}
The condensation of potassium acyltrifluoroborates (KATs) and hydroxylamines occurs under ambient, aqueous conditions to form KAT nitrones in a reversible manner. The KAT nitrones exchange rapidly under aqueous acidic conditions, resulting in a dynamic covalent library that can be converted to the corresponding static amides by treatment with strong acid. Extensive studies on the conditions and kinetics show that - counterintuitively - KAT nitrone formation is accelerated by water. The overall process serves as a dynamic system operating at room temperature under aqueous conditions with the rare ability of trapping the mixture into stable secondary amides
\end{abstract}

\section{Introduction}

Dynamic chemistry ${ }^{1-7}$ describes a complementary approach of solving chemical problems thermodynamically, in contrast to the precise, kinetic control of reaction outcomes. Since the first usage of the term Dynamic Covalent Chemistry (DCC) by Stoddart in 2002, ${ }^{6}$ various applications have been realized, including the search for drug candidates, ${ }^{8}$ molecular sensing ${ }^{9-12}$ and the production of complex momolecular machines ${ }^{13,14}$ and functional materials. ${ }^{15,16}$ Covalent bonds that form reversibly are pivotal in dynamic chemical systems. Examples include imines ${ }^{7}$, hydrazones ${ }^{17,18}$, oximes ${ }^{19}$ and nitrones ${ }^{20-22}$ that are in equilibrium with their constituent carbonyl compounds and amine derivatives. Disulfides ${ }^{8}$ and diselenides ${ }^{23}$ have also been found to exchange reversibly in redox buffers. Boronates ${ }^{24-26}$ and carboxylate esters ${ }^{27,28}$ have also been used to construct a dynamic chemical systems. Unfortunately, many of these conditions for the exchange of dynamic chemical bonds may interfere with the system under study. For example, in the case of identifying ligands for protein targets, endogenous cysteine 
residues may interfere with disulfide bonds exchange, and lysine residues may react under imine formation conditions.

The inherent instability of dynamic covalent bonds poses another challenge on dynamic chemical systems. To read out information from the dynamic chemical system without complications, it is desirable to convert or "fix" the formed dynamic bonds to a static bond prior to analysis, for example by the reduction of dynamic imine bonds to saturated amines. ${ }^{29}$ In the field of dynamic amide bond formation, the conversion of an imine COF to an amide COF has been demonstrated. ${ }^{30}$ There has also been examples where amide bonds can be formed and exchanged reversibly, however special conditions such as electrophilic activation in anhydrous environment, ${ }^{31} \mathrm{NCL}$ conditions, ${ }^{32}$ enzymes ${ }^{33}$ or Lewis acids ${ }^{34}$ are needed.

In this manuscript, we disclose a dynamic chemical system that can form amide bonds under ambient acidic conditions, via the intermediacy of nitrones that are formed dynamically under dilute, aqueous conditions from a KAT and a hydroxylamine.

Potassium Acyltrifluoroborates (KATs) are a class of bench stable compounds with versatile reactivity, and have recently found various applications in bioconjugation ${ }^{35-37}$ and material science ${ }^{38-42}$ due to their ability to undergo rapid ligations ${ }^{43,44}$ with $\mathrm{O}$-substituted hydroxylamines or $\mathrm{N}$-chloro amines under mild and dilute conditions to form amides. The union of $O$-unsubstituted hydroxylamines and KATs, however, results in a nitrone ${ }^{45}$ which upon further activation can rearrangement to an amide. We envision that this reactivity, depicted in Scheme 1, may act as a dynamic chemical system ${ }^{1,2,6,7,46}$ resulting ultimately in the formation of amide bonds. We report here the formation of KAT nitrones and their dynamic exchange, as characterized by ${ }^{1} \mathrm{H}$ NMR, UV-Vis and LCMS, and validate its potential as a dynamic chemical system.

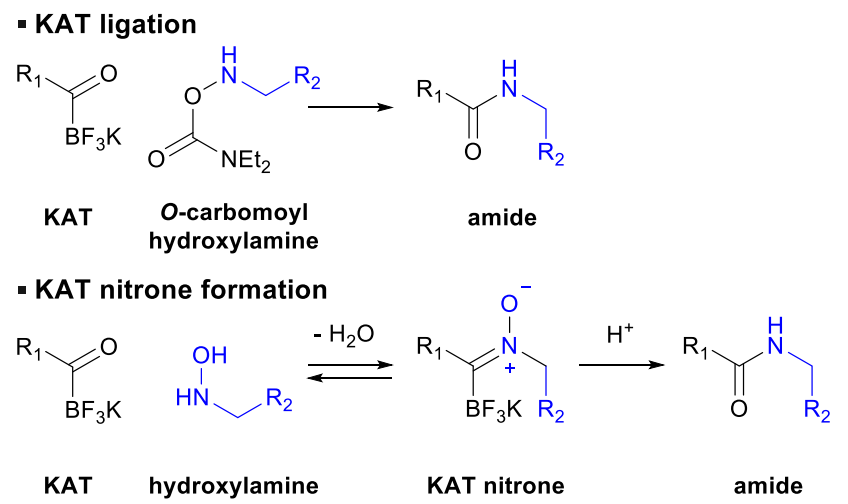

Scheme 1. KATs and hydroxylamines form KAT nitrones reversibly, and furnishes an amide when acidified in a dynamic covalent amide-forming system. 


\section{Results and Discussion}

\section{Conditions and kinetics of KAT nitrone formation.}

We selected $p$-bromophenyl KAT 1 and $N$-benzyl hydroxylamine 2 as the standard substrates for identifying suitable conditions for KAT nitrone formation, with particular regards to the reaction solvents (

Table 1). Initial screening revealed that polar aprotic solvents such as acetone, $\mathrm{CH}_{3} \mathrm{CN}$, DMF, or DMSO were needed to dissolve KAT 1, which was crucial for the facile formation of nitrone 3 . Acetone and $\mathrm{CH}_{3} \mathrm{CN}$ were less desirable solvents due to their the formation of side products with hydroxylamine 2 (See SI). Both DMF and DMSO were suitable for KAT nitrone formation at $0.1 \mathrm{M}$ concentration; however, after investigating the rate of nitrone formation at lower concentrations we discovered that the reaction rate depended on the content of water or other protic solvents such as HFIP and $\mathrm{MeOH}$ in the reaction mixture (entries $12-16$ ). The nitrone formation rate was found to be fastest when HFIP was used as a co-solvent, although $\mathrm{H}_{2} \mathrm{O}$ and $\mathrm{MeOH}$ also gave good results. In aqueous DMSO mixtures of various water content, the rates were found to be faster with higher concentrations of $\mathrm{H}_{2} \mathrm{O}$. This rendered rate measurements in pure DMSO complicated, as the nitrone formation produces one equivalence of $\mathrm{H}_{2} \mathrm{O}$, resulting in autocatalysis. Therefore we chose $1: 1 \mathrm{~d} 6-\mathrm{DMSO}-\mathrm{D}_{2} \mathrm{O}$ as the standard solvent to study the KAT nitrone formation with ${ }^{1} \mathrm{H}$ NMR in. Similar to typical aldo- and ketonitrone formation, KAT nitrone formation was accelerated at lower $\mathrm{pH}$ (3.8), with the difference being that KAT nitrone can still form smoothly without requiring anhydrous conditions or catalysis, even under dilute neutral aqueous solutions, and we hypothesized that acid catalysis may be responsible for this kinetic solvent dependence. Figure 1 shows that with varying buffer concentrations at constant $\mathrm{pH}$, the formation of KAT nitrone varied slightly, suggesting the presence of general acid catalysis in KAT nitrone formation, which may as well explain its solvent dependency. 


\section{Dzeng and Bode}

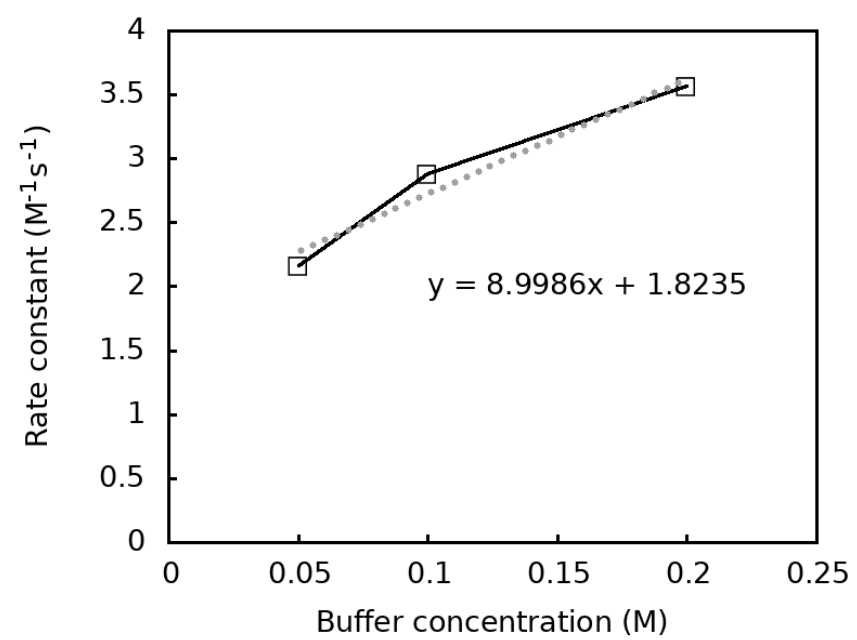

Figure 1. Observed rate constant of KAT nitrone 3 formation in DMSO-AcOK buffer of various concentrations.

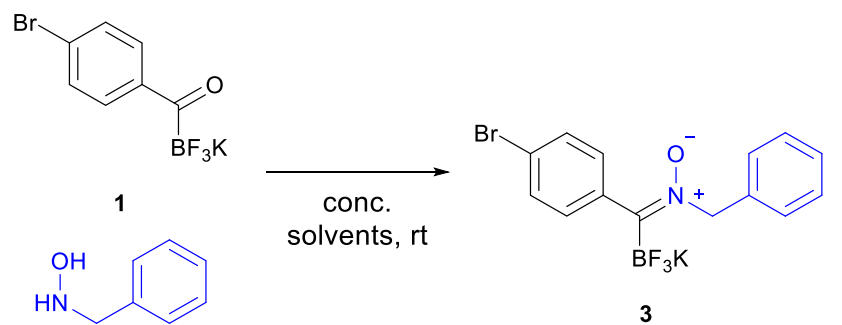

\begin{tabular}{|c|c|c|c|}
\hline Entry & Solvent & Conc. & Outcome / $k$ \\
\hline 1 & Acetone & $0.1 \mathrm{M}$ & Reacts with 2 \\
\hline 2 & $\mathrm{CH}_{3} \mathrm{CN}$ & $0.1 \mathrm{M}$ & $>90 \%{ }^{a}$ \\
\hline 3 & EtOAc & $0.1 \mathrm{M}$ & 1 insoluble \\
\hline 4 & THF & $0.1 \mathrm{M}$ & 1 insoluble \\
\hline 5 & $\mathrm{H}_{2} \mathrm{O}$ & $0.1 \mathrm{M}$ & 1 insoluble \\
\hline 6 & Methanol & $0.1 \mathrm{M}$ & 1 insoluble \\
\hline 7 & DMF & $0.1 \mathrm{M}$ & $>90 \%{ }^{b}$ \\
\hline 8 & DMSO & $0.1 \mathrm{M}$ & $>90 \%{ }^{\mathrm{b}}$ \\
\hline 9 & DMSO & $10 \mathrm{mM}$ & N.A. ${ }^{d}$ \\
\hline 10 & $\mathrm{CH}_{3} \mathrm{CN}-\mathrm{H}_{2} \mathrm{O}$ & $0.1 \mathrm{M}$ & $>90 \% c$ \\
\hline 11 & 9:1 DMSO- $\mathrm{H}_{2} \mathrm{O}$ & $10 \mathrm{mM}$ & N.A. ${ }^{d}$ \\
\hline 12 & 3:1 DMSO- $\mathrm{H}_{2} \mathrm{O}$ & $10 \mathrm{mM}$ & $3 \times 10^{-2} \mathrm{M}^{-1} \mathrm{~s}^{-1}$ \\
\hline 13 & 1:9 DMSO- $\mathrm{H}_{2} \mathrm{O}$ & $10 \mathrm{mM}$ & $2 \times 10^{-1} \mathrm{M}^{-1} \mathrm{~s}^{-1}$ \\
\hline 14 & $1: 1 \mathrm{DMSO}-\mathrm{H}_{2} \mathrm{O}$ & $10 \mathrm{mM}$ & $8.67 \times 10^{-2} \mathrm{M}^{-1} \mathrm{~s}^{-1}$ \\
\hline 15 & 1:1 DMSO-MeOH & $10 \mathrm{mM}$ & $7.03 \times 10^{-4} \mathrm{M}^{-1} \mathrm{~s}^{-1}$ \\
\hline 16 & 1:1 DMSO-HFIP & $10 \mathrm{mM}$ & $1.59 \times 10^{-1} \mathrm{M}^{-1} \mathrm{~s}^{-1}$ \\
\hline 17 & $\begin{array}{l}\text { 1:1 DMSO } \\
0.05 \mathrm{M} \text { AcOK buffer }\end{array}$ & $10 \mathrm{mM}$ & $2.17 \mathrm{M}^{-1} \mathrm{~s}^{-1}$ \\
\hline 18 & $\begin{array}{l}\text { 1:1 DMSO } \\
0.1 \mathrm{M} \text { AcOK buffer }\end{array}$ & $10 \mathrm{mM}$ & $2.88 \mathrm{M}^{-1} \mathrm{~s}^{-1}$ \\
\hline
\end{tabular}


Table 1. Solvent effect on KAT nitrone formation. Yields were estimated with LCMS analysis of the reaction mixture. Rate constants were measured either by NMR or UV-Vis. a: $\mathrm{CH}_{3} \mathrm{CN}$ reacts with hydroxylamine 2 slowly. b: These solvents were hard to remove, and sometimes co-elute during preparative chromatography. c: This solvent mixture works well for the dissolution of di- and tris-KATs. d: These rates were too slow to be measured within 2 days.

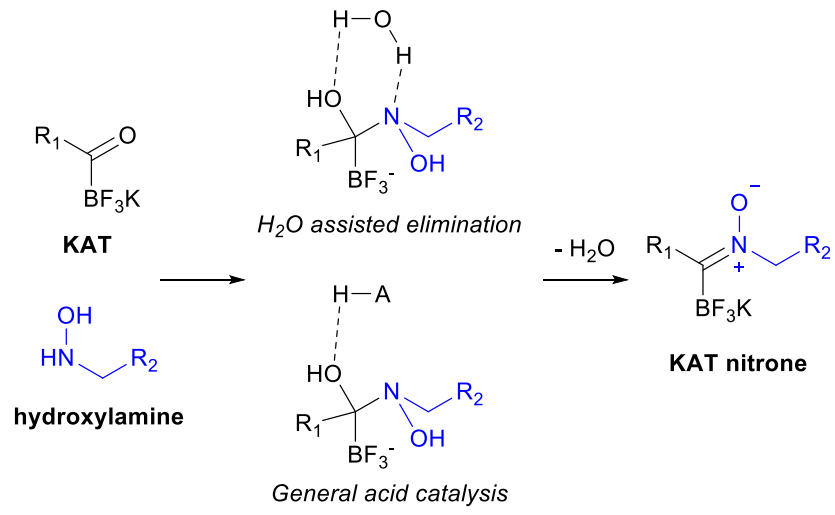

Scheme 2. Proposed mechanism of KAT nitrone formation based on the observed rate and acid dependency of reaction rates. Water and acid are suspected to assist the formation of the hemiaminal intermediate through bronsted acid catalysis.

KAT nitrone formation with a range of other KATs $(4-7)$ was investigated under the standard conditions established with KAT 1, which was $10 \mathrm{mM}$ in 1:1 DMSO- $\mathrm{D}_{2} \mathrm{O}$ with equimolar hydroxylamine 2. The rate constant was obtained with the assumption that nitrone formation follows a second order rate law, namely with reaction rate being $\boldsymbol{k}[K A T][2]$, and the obtained rate constants were summarized in Scheme 3. The rate constants were found to be in the range of $0.008 \sim 0.6 \mathrm{M}^{-1} \mathrm{~s}^{-1}$ depending the structure of the KAT, with pyridyl KAT 6 giving the fastest nitrone forming rate. For KAT 1, the nitrone formation rate was found to be more than 20 times faster at $\mathrm{pH} 3.8$, as compared to neutral conditions. 


\section{Dzeng and Bode}

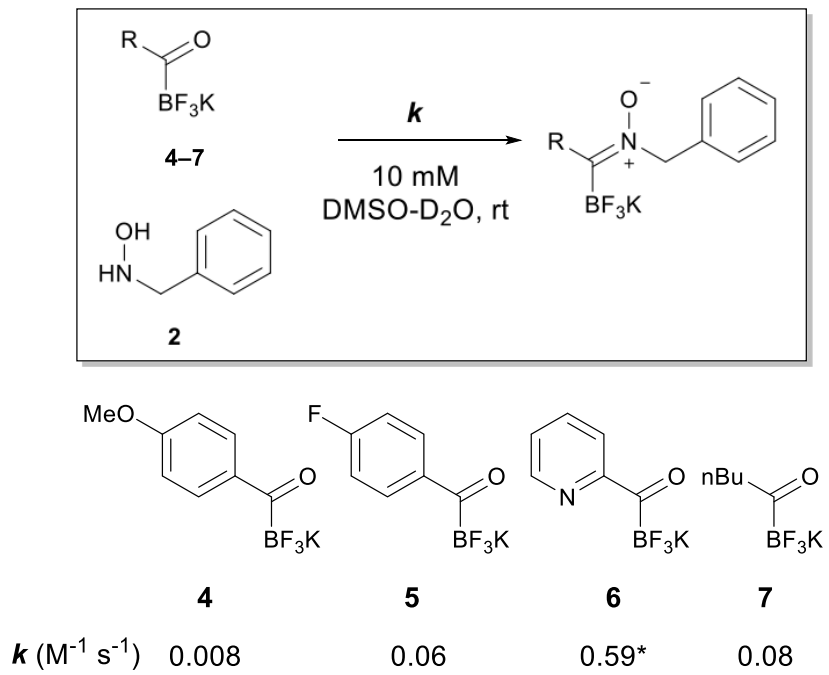

Scheme 3. Second order reaction rates of KAT nitrone formation. ${ }^{*}$ : This rate constant was too fast to measure with ${ }^{1} \mathrm{H}$ NMR and was performed with UV-Vis. 


\section{Conditions for conversion of KAT nitrones to amides}

Strong aqueous acidic conditions promoted the conversion of KAT nitrones to amides. Table 2 listed the conditions screened using KAT nitrone $\mathbf{3}$ with various acid solutions; the reaction outcomes were assessed by LCMS. $\mathrm{HCl}_{(\mathrm{aq})}$ in concentrations higher than $2 \mathrm{M}$ successfully converted KAT nitrone 3 to amide 8, whereas other acids, mostly with a $p K_{a}$ higher than that of oxalic acid $\left(p K_{a}=1.2\right)$, did not give significant conversions.

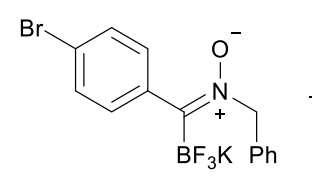

3

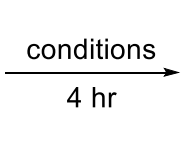

hr

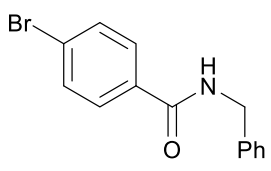

8

\begin{tabular}{|c|c|c|}
\hline Entry & Conditions & Outcome \\
\hline 1 & $2 \mathrm{M}$ oxalic acid(aq) & $<1 \%$ \\
\hline 2 & 2 M Formic $\operatorname{acid}_{(a q)}$ & n.r. \\
\hline 3 & $2 \mathrm{M}$ dichloroacetic $\operatorname{acid}_{(\mathrm{aq})}$ & n.r. \\
\hline 4 & $2 \mathrm{M} \mathrm{HF}_{(\mathrm{aq})}$ & n.r. \\
\hline 5 & $2 \mathrm{M} \mathrm{H}_{2} \mathrm{SO}_{4(\mathrm{aq})}$ & n.r. \\
\hline 6 & $0.6 \mathrm{M} \mathrm{HCl}_{(\mathrm{aq})}$ & n.r. \\
\hline 7 & $1.2 \mathrm{M} \mathrm{HCl}_{(\mathrm{aq})}$ & n.r. \\
\hline 8 & $2.0 \mathrm{M} \mathrm{HCl}_{(\mathrm{aq})}$ & $>50 \%$ \\
\hline 9 & $2.0 \mathrm{M} \mathrm{HCl}_{(\mathrm{aq})}, 60^{\circ} \mathrm{C}$ & $>99 \%$ \\
\hline 10 & $2.0 \mathrm{M} \mathrm{HBF}_{4(\mathrm{aq})}$ & $>50 \%$ \\
\hline
\end{tabular}

Table 2. Acidic conditions for conversion of KAT nitrone 3 into amide 8 . The initial nitrone concentration was $10 \mathrm{mM}$.

\section{Exchange of KAT nitrone and "snapshot" fixation}

To better probe the exchange of the nitrone partners an isotopomer exchange experiment was performed. Nitrones 3 and $\mathbf{1 0}$ were prepared and mixed in a 1:1 fashion and left to exchange, forming nitrones 9 and 11. The hydroxylamine used in $\mathbf{3}$ was benzyl hydroxylamine, and its isotopically labeled version d7-benzyl hydroxylamine was used in 10, making the nitrones 9 / 3 a pair of isotopomers, and 11 / 10 another pair of isotopomers. As the KATs and hydroxylamines exchange a statistical mixture will be reached in which [9]:[3] and [11]:[10] approach unity. We assume the ionization yield in LCMS for isotopomers to be the same, so that ion count ratios of isotopomers from LC-ESI-MS analysis may serve as a good estimate of the actual ratio between isotopomer concentrations, which is an indicator of the exchange process. The exchange experiment was performed in both $\mathrm{pH} 5$ acetate buffer $(50 \mathrm{mM})$ and $\mathrm{pH} 3$ citrate buffer $(50 \mathrm{mM})$, with the initial nitrone concentrations being $10 \mathrm{mM}$ each. LCMS analysis 
was after certain time durations and the change of isotopomer ion count ratios over time were plotted below in Figure 2.

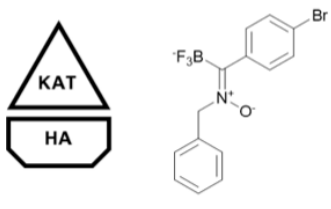

KAT

HA

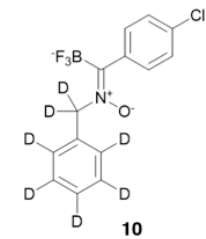

10
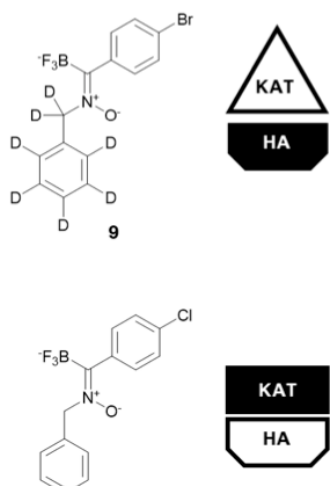

11

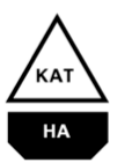

KAT

HA

$\mathrm{pH} 311 / 10 \square \mathrm{pH} 59 / 3$ $\mathrm{pH} 39 / 3 \triangle \mathrm{pH} 511 / 10$

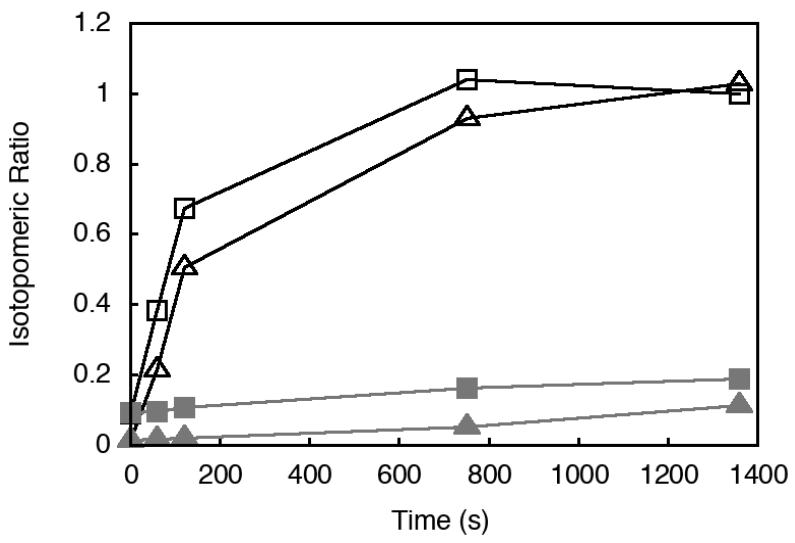

Figure 2. Nitrone isotopomer exchange experiment shows the istopomeric ratios approach unity over time as the nitrones scramble to a statistical mixture. Isotopomeric ratios were obtained by integration of the mass channel of LCMS data (355 $359 \mathrm{Da}$ for 3, $362-366 \mathrm{Da}$ for 9, 318 - 322 Da and 311 - $315 \mathrm{Da}$ for 10 and 11 respectively). The equilibration progression at $\mathrm{pH} 3$ is depicted by the solid black data points, and is much faster than that observed at $\mathrm{pH} 5$.

Acidic conditions - which fix the KAT nitrone into a persistent amide linkage - can also promotes nitrone exchange. We therefore wished to find strong acidic conditions that quickly formed the amides from the nitrones present at a specific time point; i.e. condition that could provide a "snapshot" of the offequilibrium system, such as that depicted in Scheme 4A. To achieve this, nitrone 13 was dissolved in 1:1 DMSO- $\mathrm{H}_{2} \mathrm{O}-10 \% \mathrm{AcOH}$ to form a $2 \mathrm{mM}$ solution. To this solution,1 equiv of $d 7$-hydroxylamine 12 was added to exchange with the $h 7$-hydroxylamine part of 13. At 30s, 60s, 120s, 240s, and 480s after the addition of $d 7$-hydroxylamine 12, a portion of the reaction mixture was mixed with an equal volume of $12 \mathrm{M} \mathrm{HCl}_{(\mathrm{aq})}$ to take a "snapshot" of the distribution of nitrones, represented by the relative 
concentration of amides 15 and 16 measured with LCMS. The values of [15]:[16] were plotted against reaction time and were shown to change over time to approach unity in Scheme 4A.

A)<smiles>[2H]c1c([2H])c([2H])c(CNO)c([2H])c1[2H]</smiles>

12

13<smiles>O=C(NCc1ccccc1)c1ccccn1</smiles>

16

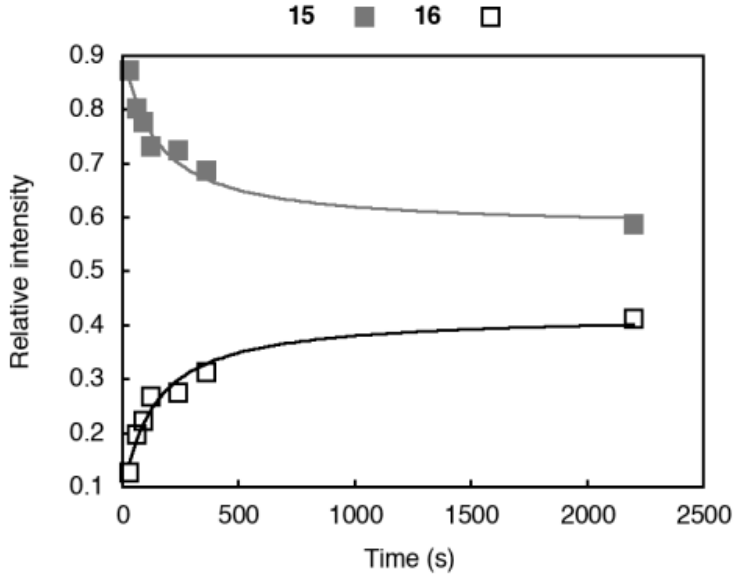

2 $\stackrel{6 \mathrm{M} \mathrm{HCl}}{\longrightarrow}$<smiles>CCc1ccccc1</smiles><smiles>[2H]c1c([2H])c([2H])c(C[N+]([O-])=C([18O])c2ccccn2)c([2H])c1[2H]</smiles>

14
15<smiles>[2H]c1c([2H])c([2H])c(CNC(=O)c2ccccn2)c([2H])c1[2H]</smiles>

B)

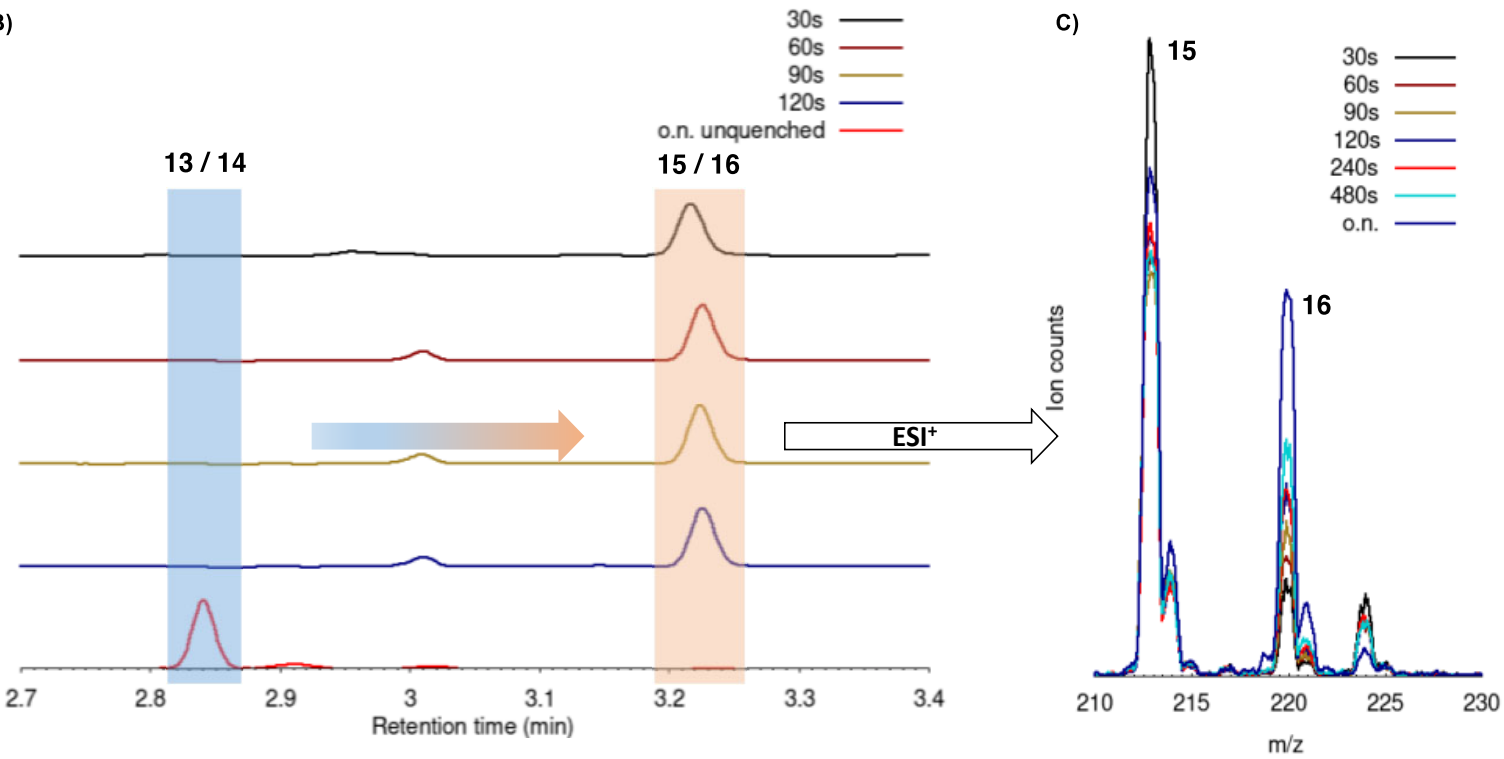

Scheme 4. A) In a "snapshot" experiment the hydroxylamine part of nitrone $\mathbf{1 3}$ was substituted with hydroxylamine $\mathbf{1 2}$ in $10 \%$ acetic acid, and were fixed to amides by $6 \mathrm{M} \mathrm{HCl}$. The relative intensities of 15 and 16 were plotted against the time before quenching with $\mathrm{HCl}$. B) LCMS chromatogram of the quenched mixture after 30,60, 90, $120 \mathrm{~s}$ of mixing, plus that of the unquenched mixture stood overnight. The formation of amide is complete, when and only when the $6 \mathrm{M} \mathrm{HCl}$ quench was performed. C) The ESI+ spectrum extracted from the amide peak retention time region from different quench time showed the decrease of $\mathbf{1 5}$ abundance and the increase of 16 intensity over time.

LCMS chromatograms (Scheme 4B) from the snapshots also indicated complete conversion of nitrone to amide within the $\sim 2$ minute time between acidification and LCMS injection, where as the nitronecontaining reaction mixture stored overnight underwent minimal amide formation. The ESI+ 
mass trace (Scheme 4C) extracted from the amide peak indicated a gradual growth of the 16 abundance, and the decrease of 15 . We were pleased to see that we could use a weak acidic conditions to facilitate the nitrone exchange without prematurely fixing the dynamic exchange, and use a strong acidic conditions to quickly freeze the current state of exchange without blurring the snapshot to equilibrium state. This validated KAT nitrone exchange to be a dynamic chemistry system.

\section{KAT nitrone dynamic combinatorial library}

After validating that KAT nitrones can form dynamically and be fixed into static amides by acidification, we proceeded to demonstrate that a complex dynamic covalent library of KAT nitrones can be formed from a relatively small number of building blocks. In 1:1 DMSO/ $\mathrm{H}_{2} \mathrm{O}$ containing $10 \% \mathrm{AcOH}, \mathrm{KATs} 1,17$, 18 and hydroxylamines $2,19,20$ were mixed with an initial concentration of $\sim 50 \mu \mathrm{M}$ of each component. The reaction mixture was analyzed with LCMS and the relative abundance of species formed were shown in Scheme 5. Bis-hydroxylamine 20, in particular, generated extra complexity as it can form two different nitrone bonds with different KATs at the two hydroxylamine sites.

All 15 possible nitrone combinations were successfully identified in the extracted ion chromatogram taken 12 hours after the mixing, as well as their corresponding amide products, after acidic quenching. It is verified that KAT nitrones can be used to generate dynamic covalent libraries from dilute aqueous building block solutions.

\section{Conclusion}

KAT nitrone formation was found to be facile in aqueous solution from KATs and hydroxylamines. The formation of KAT nitrone was subjected to general acid catalysis, leading to faster nitrone formation at lower $\mathrm{pH}$ or in solvent mixtures with higher concentrations of protic solvent. The KAT nitrone formation rate for KATs were found to be pyridyl KATs > butyl KAT > phenyl KATs.

The KAT-hydroxylamine pair exchange of KAT nitrones was also found to be dynamic in aqueous solutions. The exchange rate was also $\mathrm{pH}$ dependent, with the rate being faster at lower $\mathrm{pH}$. Under strongly acidic conditions such as $6 \mathrm{M} \mathrm{HCl}$, KAT nitrones can be converted to the amides, before the KAT hydroxylamine partner exchange reaches equilibrium, rendering this a viable condition to freeze the combinations of KAT nitrone bonds. A complex dynamic covalent library of KAT nitrones can be prepared from mixing a small collection of KAT and hydroxylamine building blocks, forming nitrones of all possible combination that can be converted to the corresponding amides on demand. These findings 


\section{Dzeng and Bode}

support the conjecture that KAT nitrones can form a fixable dynamic chemical system leading to the formation of amid bonds.

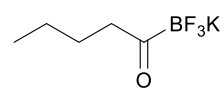

7<smiles>O=C(Br)c1ccc(Br)cc1</smiles><smiles>ONCc1ccccc1</smiles>

2

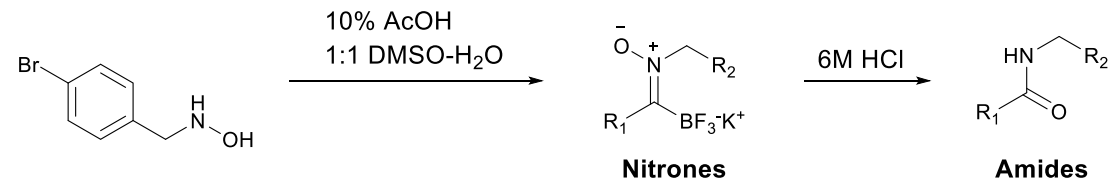<smiles>O=C(Br)COc1ccccc1</smiles>

18

19<smiles>ONCc1ccc(-c2ccc(CNO)cc2)cc1</smiles>

20

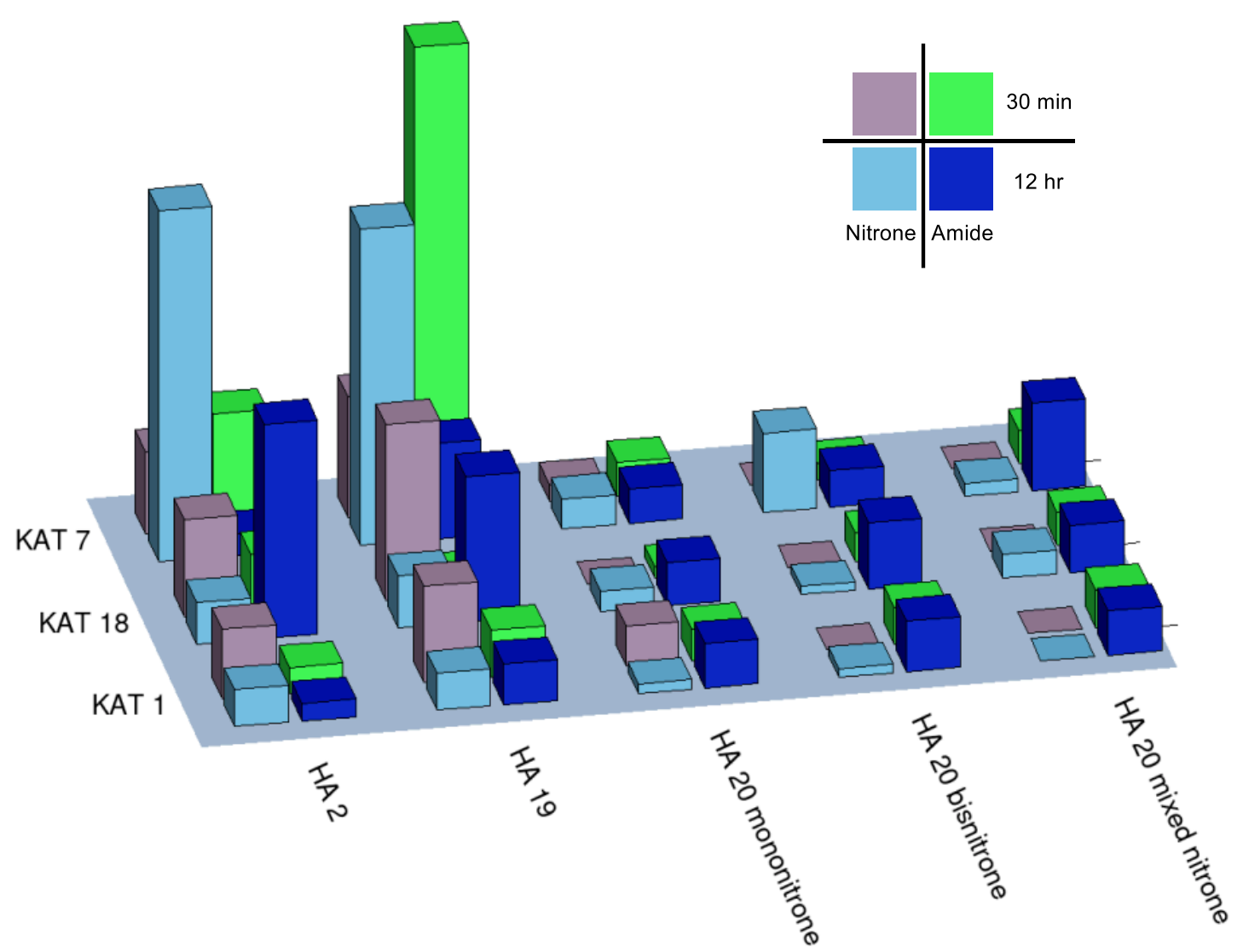

Scheme 5. The combination of KATs 1, 7, 18 and hydroxylamines 2, 19 and 20 gave rise to a dynamic nitrone library that can be fixed to an amide mixture by further acidification with $6 \mathrm{M} \mathrm{HCl}$. The relative abundance of each nitrone and its corresponding amide were measured at $30 \mathrm{~min}$ and $12 \mathrm{hr}$ after the mixing plotted as a $2 \times 2$ cluster. In each cluster, the bars in the left represent the relative abundance of the nitrone, and those on the right represent the abundance of the corresponding found upon quenching with $6 \mathrm{M} \mathrm{HCl}$. The upper bars indicate the results obtained after $30 \mathrm{~min}$ of mixing the KATs and hydroxylamines, whereas the lower ones indicate the results after $12 \mathrm{hr}$, to visualize the population of species changing over time. 
Dzeng and Bode

\section{Conflict of interest}

There are no conflicts to declare

\section{Acknowledgements}

We thank the NMR service of the Laboratorium für Organische Chemie, Small Molecule Crystallography Center (SMoCC), and Molecular and Biomolecular Analysis Service (MoBiAS) at ETH Zürich for assistance.

\section{Notes and references}

(1) Ashkenasy, G.; Hermans, T. M.; Otto, S.; Taylor, A. F. Systems Chemistry. Chem. Soc. Rev. 2017, 46, 2543-2554.

(2) Ludlow, R. F.; Otto, S. Systems Chemistry. Chem Soc Rev 2008, 37, 101-108.

(3) Corbett, P. T.; Leclaire, J.; Vial, L.; West, K. R.; Wietor, J.-L.; Sanders, J. K. M.; Otto, S. Dynamic Combinatorial Chemistry. Chem. Rev. 2006, 106, 3652-3711.

(4) Ladame, S. Dynamic Combinatorial Chemistry: On the Road to Fulfilling the Promise. Org. Biomol. Chem. 2008, 6, 219-226.

(5) Lehn, J. M. Dynamic Combinatorial Chemistry and Virtual Combinatorial Libraries. Essays Contemp. Chem. Mol. Struct. Biol. 2007, No. 9, 307-326.

(6) Rowan, S. J.; Cantrill, S. J.; Cousins, G. R. L.; Sanders, J. K. M.; Stoddart, J. F. Dynamic Covalent Chemistry. Angew. Chem. Int. Ed. 2002, 41, 898-952.

(7) Belowich, M. E.; Stoddart, J. F. Dynamic Imine Chemistry. Chem. Soc. Rev. 2012, 41, 20032024.

(8) Scott, D. E.; Dawes, G. J.; Ando, M.; Abell, C.; Ciulli, A. A Fragment-Based Approach to Probing Adenosine Recognition Sites by Using Dynamic Combinatorial Chemistry. ChemBioChem 2009, 10, 2772-2779.

(9) You, L.; Berman, J. S.; Anslyn, E. V. Dynamic Multi-Component Covalent Assembly for the Reversible Binding of Secondary Alcohols and Chirality Sensing. Nat. Chem. 2011, 3, 943-948.

(10) Herrera, B. T.; Moor, S. R.; McVeigh, M.; Roesner, E. K.; Marini, F.; Anslyn, E. V. Rapid Optical Determination of Enantiomeric Excess, Diastereomeric Excess, and Total Concentration Using Dynamic-Covalent Assemblies: A Demonstration Using 2-Aminocyclohexanol and Chemometrics. J. Am. Chem. Soc. 2019, 141, 11151-11160.

(11) Ni, C.; Zha, D.; Ye, H.; Hai, Y.; Zhou, Y.; Anslyn, E. V.; You, L. Dynamic Covalent Chemistry within Biphenyl Scaffolds: Reversible Covalent Bonding, Control of Selectivity, and Chirality Sensing with a Single System. Angew. Chem. Int. Ed. 2018, 57, 1300-1305.

(12) Schouwey, C.; Scopelliti, R.; Severin, K. An Imine-Based Molecular Cage with Distinct Binding Sites for Small and Large Alkali Metal Cations. Chem. - Eur. J. 2013, 19, 6274-6281.

(13) Balzani, V.; Credi, A.; Raymo, F. M.; Stoddart, J. F. Artificial Molecular Machines. Angew. Chem. Int. Ed. 2000, 39, 3348-3391. 
(14) Kay, E. R.; Leigh, D. A.; Zerbetto, F. Synthetic Molecular Motors and Mechanical Machines. Angew. Chem. Int. Ed. 2007, 46, 72-191.

(15) Chakma, P.; Konkolewicz, D. Dynamic Covalent Bonds in Polymeric Materials. Angew. Chem. Int. Ed. 2019.

(16) Luisier, N.; Schenk, K.; Severin, K. A Four-Component Organogel Based on Orthogonal Chemical Interactions. Chem. Commun. 2014, 50, 10233-10236.

(17) Dirksen, A.; Dirksen, S.; Hackeng, T. M.; Dawson, P. E. Nucleophilic Catalysis of Hydrazone Formation and Transimination: Implications for Dynamic Covalent Chemistry. J. Am. Chem. Soc. 2006, 128, 15602-15603.

(18) Chaur, M. N.; Collado, D.; Lehn, J. M. Configurational and Constitutional Information Storage: Multiple Dynamics in Systems Based on Pyridyl and Acyl Hydrazones. Chem. - Eur. J. 2011, 17, 248-258.

(19) Haney, C. M.; Horne, W. S. Dynamic Covalent Side-Chain Cross-Links via Intermolecular Oxime or Hydrazone Formation from Bifunctional Peptides and Simple Organic Linkers. J. Pept. Sci. 2014, 20, 108-114.

(20) Turega, S. M.; Lorenz, C.; Sadownik, J. W.; Philp, D. Target-Driven Selection in a Dynamic Nitrone Library. Chem. Commun. 2008, No. 34, 4076-4078.

(21) Richards, J. E.; Philp, D. A Reactive Nitrone-Based Organogel That Self-Assembles from Its Constituents in Chloroform. Chem. Commun. 2016, 52, 4995-4998.

(22) Sadownik, J. W.; Philp, D. A Simple Synthetic Replicator Amplifies Itself from a Dynamic Reagent Pool. Angew. Chem. Int. Ed. 2008, 47, 9965-9970.

(23) Ji, S.; Cao, W.; Yu, Y.; Xu, H. Dynamic Diselenide Bonds: Exchange Reaction Induced by Visible Light without Catalysis. Angew. Chem. - Int. Ed. 2014, 53, 6781-6785.

(24) Smith, B. J.; Dichtel, W. R. Mechanistic Studies of Two-Dimensional Covalent Organic Frameworks Rapidly Polymerized from Initially Homogenous Conditions. J. Am. Chem. Soc. 2014, 136, 8783-8789.

(25) Tamaki, K.; Ishigami, A.; Tanaka, Y.; Yamanaka, M.; Kobayashi, K. Self-Assembled Boronic Ester Cavitand Capsules with Various Bis(Catechol) Linkers: Cavity-Expanded and Chiral Capsules. Chem. - Eur. J. 2015, 21, 13714-13722.

(26) Luisier, N.; Bally, K.; Scopelliti, R.; Fadaei, F. T.; Schenk, K.; Pattison, P.; Solari, E.; Severin, K. Crystal Engineering of Polymeric Structures with Dative Boron-Nitrogen Bonds: Design Criteria and Limitations. Cryst. Growth Des. 2016, 16, 6600-6604.

(27) Fukuda, K.; Shimoda, M.; Sukegawa, M.; Nobori, T.; Lehn, J. M. Doubly Degradable Dynamers: Dynamic Covalent Polymers Based on Reversible Imine Connections and Biodegradable Polyester Units. Green Chem. 2012, 14, 2907-2911.

(28) Capelot, M.; Montarnal, D.; Tournilhac, F.; Leibler, L. Metal-Catalyzed Transesterification for Healing and Assembling of Thermosets. J. Am. Chem. Soc. 2012, 134, 7664-7667.

(29) Wu, J.; Leung, K. C.-F.; Stoddart, J. F. Efficient Production of [n]Rotaxanes by Using TemplateDirected Clipping Reactions. Proc. Natl. Acad. Sci. 2007, 104, 17266-17271.

(30) Waller, P. J.; Lyle, S. J.; Osborn Popp, T. M.; Diercks, C. S.; Reimer, J. A.; Yaghi, O. M. Chemical Conversion of Linkages in Covalent Organic Frameworks. J. Am. Chem. Soc. 2016, 138, 1551915522. 
(31) Erguven, H.; Keyzer, E. N.; Arndtsen, B. A. A Versatile Approach to Dynamic Amide Bond Formation with Imine Nucleophiles. Chem. - Eur. J. 2020, 26, 5709-5716.

(32) Ruff, Y.; Garavini, V.; Giuseppone, N. Reversible Native Chemical Ligation: A Facile Access to Dynamic Covalent Peptides. J. Am. Chem. Soc. 2014, 136, 6333-6339.

(33) Pappas, C. G.; Shafi, R.; Sasselli, I. R.; Siccardi, H.; Wang, T.; Narang, V.; Abzalimov, R.; Wijerathne, N.; Ulijn, R. V. Dynamic Peptide Libraries for the Discovery of Supramolecular Nanomaterials. Nat. Nanotechnol. 2016, 11, 960-967.

(34) Stephenson, N. A.; Zhu, J.; Gellman, S. H.; Stahl, S. S. Catalytic Transamidation Reactions Compatible with Tertiary Amide Metathesis under Ambient Conditions. J. Am. Chem. Soc. 2009, 131, 10003-10008.

(35) White, C. J.; Bode, J. W. PEGylation and Dimerization of Expressed Proteins under Near Equimolar Conditions with Potassium 2-Pyridyl Acyltrifluoroborates. ACS Cent. Sci. 2018, 4, 197206.

(36) Boross, G. N.; Schauenburg, D.; Bode, J. W. Chemoselective Derivatization of Folded Synthetic Insulin Variants with Potassium Acyltrifluoroborates (KATs). Helv. Chim. Acta 2019, 102, e1800214.

(37) Galvez, A. O.; Schaack, C. P.; Noda, H.; Bode, J. W. Chemoselective Acylation of Primary Amines and Amides with Potassium Acyltrifluoroborates under Acidic Conditions. J. Am. Chem. Soc. 2017, 139, 1826-1829.

(38) Mazunin, D.; Broguiere, N.; Zenobi-Wong, M.; Bode, J. W. Synthesis of Biocompatible PEG

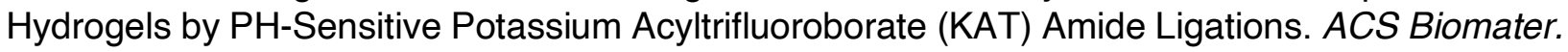
Sci. Eng. 2015, 1, 456-462.

(39) Schauenburg, D.; Osuna Gálvez, A.; Bode, J. W. Covalently Functionalized Amide Cross-Linked Hydrogels from Primary Amines and Polyethylene Glycol Acyltrifluoroborates (PEG-KATs). J. Mater. Chem. B 2018, 6, 4775-4782.

(40) Schauenburg, D.; Divandari, M.; Neumann, K.; Spiegel, C. A.; Hackett, T.; Dzeng, Y.; Spencer, N. D.; Bode, J. W. Synthesis of Polymers Containing Potassium Acyltrifluoroborates (KATs) and Post-polymerization Ligation and Conjugation. Angew. Chem. Int. Ed. 2020, 59, 14656-14663.

(41) Song, H.; Wu, D.; Mazunin, D.; Liu, S. M.; Sato, Y.; Broguiere, N.; Zenobi-Wong, M.; Bode, J. W. Post-Assembly Photomasking of Potassium Acyltrifluoroborates (KATs) for Two-Photon 3D Patterning of PEG-Hydrogels. Helv. Chim. Acta 2020, 103.

(42) Mazunin, D.; Bode, J. W. Potassium Acyltrifluoroborate (KAT) Ligations Are Orthogonal to ThiolMichael and SPAAC Reactions: Covalent Dual Immobilization of Proteins onto Synthetic PEG Hydrogels. Helv. Chim. Acta 2017, 100.

(43) Dumas, A. M.; Molander, G. a.; Bode, J. W. Amide-Forming Ligation of Acyltrifluoroborates and Hydroxylamines in Water. Angew. Chem. - Int. Ed. 2012, 51, 5683-5686.

(44) Noda, H.; Erös, G.; Bode, J. W. Rapid Ligations with Equimolar Reactants in Water with the Potassium Acyltrifluoroborate (KAT) Amide Formation. J Am Chem Soc 2014, 135, 5611-5614.

(45) Dumas, A. M.; Bode, J. W. Synthesis of Acyltrifluoroborates. Org. Lett. 2012, 14, 2138-2141.

(46) Jin, Y.; Yu, C.; Denman, R. J.; Zhang, W. Recent Advances in Dynamic Covalent Chemistry. Chem. Soc. Rev. 2013, 42, 6634. 